\title{
Traffic Creation for E-Wallet through Gamification Strategy
}

\author{
R. Seranmadevi, M. Felisiya
}

\begin{abstract}
Electronic Wallet vendors are the financial service providers to the customers using software known as an 'App'. Many customers feel more comfortable with cash free transaction as they always have a fear of insecurity to carry huge money, however every time the customer try to make purchases, they have to login, either by net banking or cards in order to complete the overall transaction. Many Electronic Wallet vendors expect huge traffic, frequent usage and customer loyalty towards their app. The gamification is emerging in e-commerce and the banks are looking for new ways to get more customers on their websites. In order to fulfill their expectation, Electronic Wallet vendors merge with ecommerce and design their app integrating gamification concept in such a way that the customers often transact and get satisfied with this application and it will reduce such huge process of net banking and make the customer to get engaged on their app. Therefore, it is important to study what are the most appreciated features of the website that could influence the behavior of the customer to use an electronic banking system with gaming features. Gaming techniques in Electronic Wallet app emerged as a dominant strategy in the digital payment space. E-commerce players and Electronic Wallet vendors have to make easy guidance, incentivize, and personalized experiences to the customers in order to achieve maximum conversions.
\end{abstract}

Keywords: e-commerce, e-Wallet, Mobile banking, Gamification.

\section{INTRODUCTION}

Gamification, a vibrant strategy is likely to induce the provider as well as the user simultaneously when it is performed. The way of attraction initiated from the basic needs of the user as underlined by the Maslow's Hierarchy theory. The financial motivations always stimulate the people to perform the activity in full tact and they could become the loyal and referral group for the same to their fellow groups. Once the need is promptly being identified, then it is very easy in the part of the provider to design the services to attain the best fit of the expectations of the users. It includes the strategy like Cash back offer, Scratch card, Lucky drop, Transact and Earn, Refer and Earn, Coupons, Gift coupons - coupon can be gifted to someone, Offers at member establishment, and Gift voucher. Gone are those days, where people used to wait for a long time to get cash in their hands. Then they utilize the money for their need and sometime it takes more than a month to get the needy. System develops and people got the money by bank account within a day and later within an hour.

Revised Manuscript Received on December 30, 2019.

* Correspondence Author

R. Seranmadevi, Associate Professor, Vel Tech Rangarajan Dr.Sagunthala R\&D Institute of Science and Technology, Chennai (Tamil Nadu) India. M. Felisiya, Associate Professor, Vel Tech Rangarajan Dr.Sagunthala R\&D Institute of Science and Technology, Chennai (Tamil Nadu) India.

(C) The Authors. Published by Blue Eyes Intelligence Engineering and Sciences Publication (BEIESP). This is an open access article under the CC BY-NC-ND license (http://creativecommons.org/licenses/by-nc-nd/4.0/)
Now-a-days we all need is to make our mind and things will be around you because digital cash wallet removed such a huge hindrance faced by many customers.Electronic wallet is an important virtual payment instrument where you can transfer money from your bank account or credit card to use for e-commerce transactions on this platform. When the gaming element merged in to this, then can expect more customer engagement in this app.

Some of the games are financial literacy quizzes, and players who do well can graduate to a level that allows them to play. Players learn basic financial management and life skills, working their way up levels by mastering life lessons and making wise financial decisions. It helps in keeping digital assets too. It is designed to make the shopping process more entertaining and add some hidden motivators for customers to visit your website more often and facilitate to feel comfort. Electronic wallet vendors provide gaming experience, where the customer has a chance to win the product for free through a lucky lottery, effects to double the click through rate in conversion.

\section{REVIEW OF LITERATURE}

The following are the review of literatures supporting to the present scope of the study, different research pioneers are escalating the gamification strategy in different fields and industry.

\section{ThịThảoHiềnBùi\&HiếuTrungBùi}

(2018), underlined the purpose of extending the understanding of the antecedents for mobile payment acceptance and further investigating the application of gamification in this environment, they employed the model of innovative technology, UTAUT with 6 variables namely performance, expectancy, effort expectancy, social influence, trust, perceived financial cost and gamification. The findings reveal there are merely substantial differences in intention to adopt technology between high school students and undergraduate as well as between undergraduates and graduates. As a result, there are significant evidences for the relationship between independent variables, namely performance expectancy, effort expectancy, trust as well as gamification, and dependent variable, adoption intention.

Meaghan C. Lister (2015), claims that Gamification involves incorporating elements of computer games such as points, leaderboards, and badges into non-game contexts in order to take advantage of the motivation provided by a game environment. An analysis of the literature was conducted to determine to what extent gamification supports student achievement and motivation among college level students.

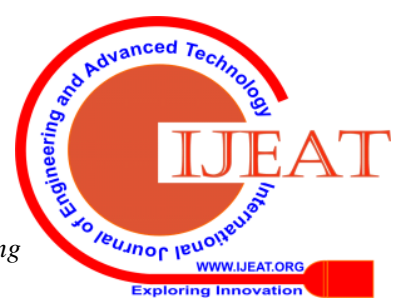


The findings from the analysis revealed that points, badges and achievements, leaderboards and levels are the most commonly implemented form of gamification. This is significant, as colleges and universities strive to attract, retain, and engage digitally savvy students who are increasingly demanding engaging, technologically rich, learning environments.

Jinimol P, ( 2018), explored about e-wallet which comes under the legally recognized term -"Prepaid Payment Instrument". Prepaid payment instruments are defined in the RBI guidelines issued under the payment and settlement system act 2005. As payment instrument that facilitate purchase of goods and services, including fund transfer, against the value stored on such instrument. The value stored on such instrument represents the value paid for by holders, by cash, by debit or a bank account or by credit card. The Prepaid payment instrument can be issued as smart cards, magnetic stripe card, internet accounts, internet wallets, mobile accounts, mobile wallets, paper vouchers and any such instruments which can be used to access the prepaid amount. Unlike other prepaid payment instruments, e-wallet is only an internet based online account. Mobile wallet is an e-wallet where the mobile phone get doubled up as an electronic wallet. Being prepaid payment instrument, digital or e-wallet is also subject to be regulation stipulated by RBI for such instrument.

Asmara Indahingwati, et.al., (2019) mentioned the important role of millennial in terms of making consumer purchasing decisions through extracting digital information as a reliable reference source and can even be a source of inspiration. Consumer behaviour for millennial and generation $\mathrm{Y}$ in the era of economic sharing, which is more dominantly involving technological factors now has provided many significant changes in terms of shopping decision making. Millennial and Y generation purchases are those that prefer to buy after getting information from User Generated Content (UGC) or based on testimonials and user experience. The pattern of purchasing decisions by consumers involves several determinants that come from within the consumer itself, such as emotional perceptions of the product seen and mood conditions when viewing or wanting to shop. Of course, this psychological condition can also be a bridge for individuals to decide whether someone will buy rationally or irrationally. On the other hand, the cognitive aspects of the internal factor sub-section refer to the extent of understanding, thought and acceptance of information for individuals who will then form a series of considerations that participate in contributing to the final attitude of individuals to decision making to have products of goods or services they want. Positive cognitive aspects will also provide positive feedback for consumers to buy a product, as well as negative feedback or bad experience that has been obtained by consumers before it is also a strong consideration to refuse to buy a product/service product. In its journey, humans, as complex social creatures, cannot be separated from elements such as ethics, morals and norms in behaving, including in terms of purchases.

The gap identified from the review of literature survey is enormous studies are undergone recently by various pioneers to explore the importance, influence and contribution of gamification strategies in different industry

and different platform. Even there are some studies very relevant to the objectives of the present study also found in different soil but not in study area and with the defined set of influencing variables. Hence, the present study is unique and distinctive of its own to evaluate the importance of gamification in deriving the traffic for electronic wallets applications.

\section{STATEMENT OF PROBLEM}

Besides the various financial services being floated by different vendors and banking services to attract the customers, it is needed to build the traffic for their e-wallet app by engaging the customers. To facilitate the services concurrently and continuously the electronic wallet vendors need a set of loyal cum engaged customers, so that it will enhance them to develop co-relations with multiple member establishments and other services providers, in order to design attractive and simulative gamification strategy. In these days, people like to taste the sweet directly from the root not even waiting to grow the tree and get the fruit. To fulfill the nurture and urgent needs, all their endeavors has to be finished as early as possible with the provision complete easiness, safety and assures security. Hence the emergence of gamification is inevitable, to retain the customer base for any electronic wallet vendors to satisfy the needs of millennium year customer groups.

\section{OBJECTIVES OF THE STUDY}

The following are the objectives of the study, attempting to narrate the importance of gamification strategy in increasing the utilization rate of electronic wallet services by the college students; those are born in millennium year.

- $\quad$ To identify the effective gamification strategy among the college students

- To analyze the gamification support mechanism facilitating e-wallet traffic

- $\quad$ To examine the level of utilization of different services offered by e-wallet vendors

- $\quad$ To evaluate the impact of gamification strategy in e-wallet service utilization

\section{SCOPE OF THE STUDY}

In this study, gamification strategy is used in financial services offering through electronic wallet vendors. The gamification strategy can be unanimously used in different field to stimulate the different participants and direct them to reach the sustainable development and great honour of achievement. The gamification strategy in book reading will helps the students' reading habit and by the way they can earn points and the same points can be converted in to cash in later days. The reward point gamification strategy is the one which will have wider application in many areas like recusing absenteeism and controlling labour turnover, inducing the productivity, cost control mechanisms, achievement of continuous improvement and so on in different field where the large numbers of employees are engaged in performing tasks. 


\section{Methodology of the study}

The penetration of mobile phone is vigorous among the millennium customers.

It is a universal truth that, owing mobile phone is not luxurious but it is a basic need. No one can live without mobile phone but the breakfast. To use this mobile phone handy culture, many financial service providers want to escalate the customer segment to their companies' platform. In order to attract, cover and retain them with their companies' product and services in the long run, they have to think in lateral way and adopt diversified mechanisms to engage and whisper them with great tolerance power. The gamification strategy is one among the greatest tool which will enhance them to keep their customer base sustain and loyal. The methodology of the study is focusing upon the interest and preference of different financial services offered by the electronic wallet vendors to attract the college students. The descriptive research design is adopted to describe the mid set and preference of the millennium year customers. The complete study is focused on college students irrespective of the degree they are studying but they belong to 16 to 19 years of age group. The study area is Chennai city, the total number of college students studying at various discipline in the study is infinite. Hence, it is proposed to use the non-probability sampling and convenience sampling technique is considered as opt one. The statement related with the preference of financial services, factors influencing them to prefer the electronic wallets and throughput of the service providers are administrated through structured questionnaire and the same was circulated among the students through Google form and the results are properly coded and classified using statistical software SPSSv.21. Appropriate statistical tools are employed to evaluate the stated objectives and derive the findings and conclusion.

\section{LIMITATIONS OF THE STUDY}

The study is subject to the following limitations,

- The area of the study is restricted only in Chennai city.

- The population consists of only the college students between 16 to 19 years age group.

- It is applicable to the person who familiarizes the gamification strategy offered by electronic wallet vendors.

\section{ANALYSIS AND DISCUSSIONS}

The structural equation model was created to exhibit the multi-level relationship among the gamification strategies, facilities being offered by the mobile application vendors through electronic wallets, and the factors which are influencing the millennial customers to develop the traffic for the electronic wallet facilities. There are ten different gamification strategies are enrolled to attract the millennial customers towards the application facilities offered through the mobile vendors. There are nine factors influencing the millennial customer to opt for the application facilities offered through the electronic wallet by mobile vendors. The influence of Age and qualification on the preference of the gaming strategies and influencing factors also be studied through this model. The structural equation model was done

through confirmatory factor analysis after performing the Kaizer Normalization. The goodness of fit indices are valued through the statistical output of the confirmatory factor analysis. The chi-square value reveals the best associations between the variables in the defined model. Other than the chi-square analysis, the other goodness of fit indices like GFI, adjusted goodness of fit indices (AGFI), CFI and TLI are also verifies to confirm the fitness of the model.

The biased opinion of the respondents may have influence the chi-square value of the model again, the sample size also an important influencing factor for determining the originality of chi-square analysis. The RMR and RMSEA help to identify the nature and extend of the error affecting the fitness of the model through evaluating the root mean square approximation method. The social studies suggesting that the results of goodness of fit indices showing more than .90 are assumed to be the best model. The statistical result of the confirmatory factor analysis of the present model also reflects the goodness of fit indices is more than the suggested level, so the constructed model is considered as best fit.

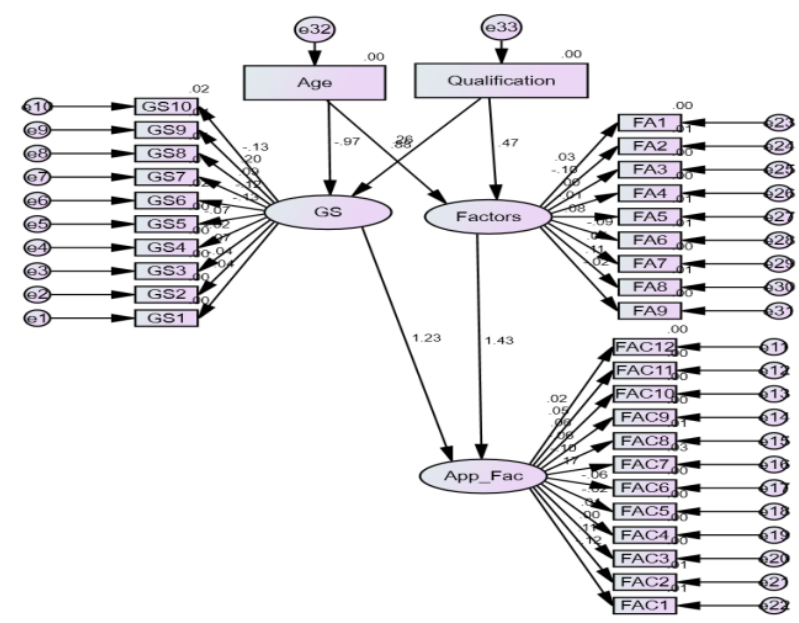

Figure 1 depicting the influence of Gamification strategy on E-wallet Traffic creation

The following table exhibits the results of the confirmatory factor analysis or the constructed model influence of Gamification strategy on E-wallet Traffic creation.

Table displaying the Result of Confirmatory Factor analysis for the influence of Gamification strategy on Ewallet Traffic creation

\begin{tabular}{|c|c|c|c|c|c|c|c|}
\hline $\begin{array}{c}\text { Chi- } \\
\text { Square }\end{array}$ & P & GFI & AGFI & CFI & TLI & RMR & RMSEA \\
\hline 107.236 & .000 & .921 & .937 & .928 & .911 & .026 & .063 \\
\hline
\end{tabular}

From the result summary of confirmatory factor analysis, it was verified that all the goodness of fit indices like GFI, AGFI, CFI are exhibiting the above suggested significant level and contribute the best of goodness of fit for the developed model. 
The error value also displayed very low at the accepted level the RMSEA of the structural model shows that 0.063 , it is under the acceptance level.

Table presenting the Regression Weight

\begin{tabular}{|c|c|c|c|c|c|c|c|}
\hline & & & $\begin{array}{l}\text { StdReg } \\
\text { weight }\end{array}$ & $\begin{array}{c}\text { Unstd } \\
\text { Reg } \\
\text { weight }\end{array}$ & S.E. & C.R. & $\mathrm{P}$ \\
\hline GS & $<--$ & Age & -0.966 & -0.043 & 0.086 & -0.504 & 0.614 \\
\hline Factors & $<--$ & Age & 0.881 & 0.043 & 0.104 & 0.411 & 0.681 \\
\hline Factors & $<---$ & Qualification & 0.474 & 0.023 & 0.058 & 0.399 & 0.69 \\
\hline GS & $<--$ & Qualification & 0.26 & 0.012 & 0.025 & 0.469 & 0.639 \\
\hline App_Fac & $<---$ & Factors & 1.429 & 0.712 & 3.468 & 0.205 & 0.837 \\
\hline App_Fac & $<---$ & GS & 1.232 & 0.663 & 3.108 & 0.213 & 0.831 \\
\hline GS1 & $<---$ & GS & 0.036 & 1 & & & \\
\hline GS2 & $<---$ & GS & -0.04 & -1.503 & 3.991 & -0.377 & 0.707 \\
\hline GS3 & $<---$ & GS & 0.07 & 2.854 & 6.34 & 0.45 & 0.653 \\
\hline GS4 & $<---$ & GS & -0.017 & -0.606 & 2.788 & -0.217 & 0.828 \\
\hline GS5 & $<---$ & GS & -0.07 & -1.913 & 4.252 & -0.45 & 0.653 \\
\hline GS6 & $<---$ & GS & -0.131 & -3.97 & 8.149 & -0.487 & 0.626 \\
\hline GS7 & $<---$ & GS & -0.117 & -4.116 & 8.525 & -0.483 & 0.629 \\
\hline GS8 & $<---$ & GS & 0.093 & 3.72 & 7.895 & 0.471 & 0.638 \\
\hline GS9 & $<---$ & GS & 0.203 & 7.324 & 14.73 & 0.497 & 0.619 \\
\hline GS10 & $<---$ & GS & -0.127 & -3.338 & 6.87 & -0.486 & 0.627 \\
\hline FAC12 & $<---$ & App_Fac & 0.017 & 1 & & & \\
\hline FAC11 & $<---$ & App_Fac & 0.052 & 2.698 & 11.92 & 0.226 & 0.821 \\
\hline FAC10 & $<---$ & App_Fac & 0.057 & 3.003 & 13.15 & 0.228 & 0.819 \\
\hline FAC9 & $<---$ & App_Fac & -0.064 & -3.433 & 14.91 & -0.23 & 0.818 \\
\hline FAC8 & $<---$ & App_Fac & -0.097 & -4.449 & 18.96 & -0.235 & 0.814 \\
\hline FAC7 & $<---$ & App_Fac & 0.166 & 4.731 & 19.96 & 0.237 & 0.813 \\
\hline FAC6 & $<--$ & App_Fac & -0.059 & -2.53 & 11.05 & -0.229 & 0.819 \\
\hline FAC5 & $<---$ & App_Fac & -0.024 & -1.342 & 6.906 & -0.194 & 0.846 \\
\hline FAC4 & $<---$ & App_Fac & 0.009 & 0.597 & 5.302 & 0.113 & 0.91 \\
\hline FAC3 & $<---$ & App_Fac & -0.002 & -0.128 & 5.529 & -0.023 & 0.982 \\
\hline FAC2 & $<---$ & App_Fac & 0.115 & 7.689 & 32.62 & 0.236 & 0.814 \\
\hline FAC1 & $<---$ & App_Fac & -0.12 & -6.668 & 28.26 & -0.236 & 0.813 \\
\hline FA1 & $<---$ & Factors & 0.029 & 1 & & & \\
\hline FA2 & $<---$ & Factors & -0.105 & -3.85 & 9.697 & -0.397 & 0.691 \\
\hline FA3 & $<---$ & Factors & 0.003 & 0.075 & 1.78 & 0.042 & 0.967 \\
\hline FA4 & $<---$ & Factors & -0.007 & -0.163 & 1.745 & -0.093 & 0.926 \\
\hline FA5 & $<---$ & Factors & 0.079 & 2.592 & 6.706 & 0.387 & 0.699 \\
\hline FA6 & $<---$ & Factors & -0.094 & -3.659 & 9.297 & -0.394 & 0.694 \\
\hline FA7 & $<---$ & Factors & 0.053 & 1.984 & 5.504 & 0.36 & 0.719 \\
\hline FA8 & $<---$ & Factors & 0.114 & 2.752 & 6.893 & 0.399 & 0.69 \\
\hline FA9 & $<--$ & Factors & -0.019 & -0.615 & 2.734 & -0.225 & 0.822 \\
\hline
\end{tabular}

It was inferred from the regression weight table that, certain factors are exhibiting the negative relationship and certain factors are exhibiting the positive relationship with the respective latent variables. It was verified from the result that, gamification strategies like GS2, GS4, GS5, GS6, GS7, and GS10 are explaining the negative influence FAC1, FAC3, FAC5, FAC6, FAC8, and FAC9, FA2, FA4, FA6, and FA9 towards the construction of its respective latent variables. Age and Qualification explains high degree influence on the influencing factors rather than the preference of gaming strategies. Gaming strategies and factors influencing the choice of Application facilities are considerably influencing the traffic of application facilities being offered through the electronic wallets.

\section{PRACTICAL IMPLICATIONS}

Irrespective of the age group and level of qualification the experience of gamification strategies being offered by the electronic wallet vendors are the same. Due to indiscrimination of offering the gamification strategies and its generic nature given opportunity to everyone to experience the same through playing the games according to the transactions they initiated. If the mobile application vendors are discriminating the gamification strategies for different age group to attract in different forms, then age and qualification will influence the preference of gamification strategies in the electronic wallet applications. The factors which are influencing the preference of application facilities are high and the choice of gamification strategies also influencing the choice of application facilities, hence $t$ is recommended positively to design and portray the gamification strategies with highest preferable platform like high security, proper safety, assured rvacy, and so on will definitely influence the millennial respondents to utilize the electronic wallet applications in a faster and wider way.

\section{CONCLUSION}

Gamification strategy is highlighting the future investment prospects to the college students. Electronic wallet vendors clearly underline the different financial services offered through their Apps exclusively. It probes a light on the financial parameters and it stimulates the college students to learn about the principles of financial management and resource utilization through playing games. The context and offers will drastically attracts many players in it and pave a way to design a comprehensive and customized financial cum investment banking services to the millennium customers at large in near future. The rate of utilization, the choice of games, conversion venue of rewards points and spending habit will give the chance to the electronic wallet vendors to predict the behavioural pattern of the customers.

\section{REFERENCES}

1. Asmara Indahingwati..et. al.,(August 2019,) "How Digital Technology Driven Millennial Consumer Behaviour in Indonesia", Journal of Distribution Science (2019) Vol.17,No.8,pp.25-34

2. https://www.investopedia.com/terms/m/mobile-banking.asp

3. https://www.latentview.com/blog/millennial-consumer-digital-data/

4. https://www.ncbi.nlm.nih.gov/pmc/articles/PMC5680647/

5. https://www.paisabazaar.com/banking/mobile-banking/ 
6. https://www.scnsoft.com/blog/gamification-in-banking

7. Jinimol. P,( 2018), "A Study on E-Wallet" International Journal of Trend in Scientific Research and Development (IJTSRD), (June 2018),Vol.2,No.4,

8. Meaghan C. Lister (2015), "Gamification: The effect on student motivation and performance at the post-secondary level, Holland College", Issues and Trends in Educational Technology,December 2015,Vol.3,No.2,pp.1-22

9. pp.358-361

10. ThịThảoHiền Bùi1\&HiếuTrung Bùi2 (2018), "Gamification impact on the acceptance of mobile payment in HO CHI MINH city, Vietnam" ,International Journal of Social Science and Economic Research ,September 2018,Vol.3,No.9,pp.4822-4837

\section{AUTHORS PROFILE}

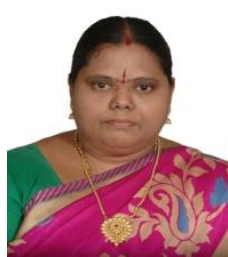

Dr. R. Seranmadevi, Associate Professor, qualified with MBA., M.Com., MCA., M.Phil., Ph.D., UGCNET(Management), and UGC-NET/JRF (Commerce), having 18.6 years of working experience both Industry and academia, presently contributing service for Vel Tech Rangarajan Dr.Sagunthala R\&D Institute of Science and Technology, Chennai under School of Management. Having publication record of various journals including Ten Scopus indexed, thirteen UGC listed, ten international and eleven national journals, presented papers in eighteen international level and twenty national level seminars. Many colleges trusted me as a resource person under different disciplines like exploring knowledge in statistical framework and Research. Extend the services for equipping the Distance education students of Anna University both MBA and MCA, and other regional universities. Serving the society by studying the fundamental issues connected to the environment; enrich them by providing proper solutions.

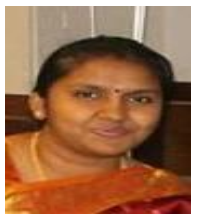

M. Felisiya qualified with B.E.,MBA and having 6 years of work experience both Industry and academic, currently working for Vel Tech Rangarajan Dr.Sagunthala R\&D Institute of Science and Technology, Chennai under School of Management as an Assistant Professor. 